\title{
Deciding priorities in Pharma
}

Maria Koehler*

It is commonly assumed that the primary objective of Pharma is to generate and maximize profit to shareholders rather than to serve humanity by the prevention and cure of disease and furthering science. Pharma is also felt to lack an incentive to fund and deliver personalized medicines, so it is up to the scientific community to do that (AT Fojo, Head of the Experimental Therapeutics Section, NCI at AACR 2010). Meanwhile, there are doubts within Pharma itself: 'increasing regulatory requirements, related escalating costs of development, and well publicized product withdrawals are leading those in the industry and its investors to wonder where future value can be realized,' (Ken Fyvie, expert in commercial strategy).

Despite this perceived pessimism, I assert to you today, that because of the rapid advances in genomics, imaging, and tumor cell biology, Pharma's priorities are now more closely aligned with those of academia than ever before.

Nearly every effective targeted agent has a biomarker that can predict response. While somatic genetic alterations in the tumor are the primary determinant of response to targeted therapy, multiple somatic genetic abnormalities are present in each tumor so both finding the critical mutations and proving that these were in fact driving tumorigenesis was and remains challenging. However, imatinib, trastuzumab, gefitinib/erlotinib, tamoxifen and many other therapeutics on the market prove that targeting specific biomarkers can be successful in both hematological and solid tumor malignancies. Targeting can bring significant benefit to patients and unexpectedly high profits to Pharma.

Pharma now understands the value of targeting specific genetic abnormalities even in small populations. This 'low hanging fruit' still requires better understanding on how best to demonstrate the treatment to be safe and effective in these niches. Conventional approaches to drug development need to be challenged. The need to compare highly effective targeted agents to standard of care chemotherapy, the lack of biomarker testing in the community setting, tissue availability, and the ability to

*Correspondence: Maria.Koehler@pfizer.com

Pfizer, Inc., 235 East 42nd Street, New York, NY 10017, USA receive optimal pricing for higher responses in a smaller population are but a few of the challenges.

A perfect example of moving clearly in the direction science brings us is the Pfizer compound crizotinib (PF-02341066), which is a dual c-Met and ALK inhibitor that was initially developed with a c-Met focus [1]. c-MET is a frequently genetically altered receptor tyrosine kinase in human cancers (hereditary papillary renal cell carcinoma, $100 \%$; sporadic papillary renal cell carcinoma, 13\%; head and neck squamous cell carcinoma, 10\%; non-small cell lung cancer (NSCLC), 8\%; and small cell lung cancer, 13\%) or amplified (gastric carcinoma, 5 to $10 \%$; colorectal carcinoma, $4 \%$ in primary tumors and $20 \%$ in liver metastases; esophageal adenocarcinoma, 5 to $10 \%)$. The other kinase inhibited was an anaplastic lymphoma kinase (ALK), known to be present in a subset of chemosensitive anaplastic lymphomas, some neuroblastomas and in inflammatory myofibroblastic tumors, a very rare tumor. In 2007, Soda and colleagues published a Nature paper identifying ALK fusion genes [2]. Fortuitously, the phase I study was ongoing at that time with PF-02341066. Of the three objective responders in this phase I study, all had ALK translocations: one with inflammatory myofibroblastic sarcoma had a NPM-ALK translocation and two with NSCLC had a EML4-ALK translocation. Despite the extreme rarity of these abnormalities, Pfizer modified the phase I protocol to recruit patients with NSCLC harboring ALK mutations and established a close collaboration with academia. The collaborator adjusted the existing Abbott fluorescent in situ hybridization (FISH) assay and served as the reference laboratory for detecting EML4-ALK translocations in tumor specimens for patients in the trial [3]. A formal collaboration with Abbott to develop a commercialized diagnostic followed.

In a single-agent study including 82 patients reported at the 2010 American Society of Clinical Oncology (ASCO) meeting, more than half of participants with recurrent metastatic NSCLC had a RECIST (Response Evaluation Criteria In Solid Tumors) response and 82\% had clinical benefit [4]. As reported, the tolerability profile was excellent, with single digit grade 2 toxicities. The compound now will be presented to regulatory authorities for approval in a subpopulation of 3 to $5 \%$ of patients with NSCLC with an expected duration of 
treatment until progression of about 8 to 12 months. In addition, the discovery strategy in most Pharmas has evolved from designing a chemical entity and testing it in patients to first identifying key drivers of disease and then developing agents aimed at these disease pathways.

The era of broad based drug development is over and translational research is essential for additional progress against cancer. This creates new opportunities and challenges. Some of the opportunities include better insights into the complex cancer biology, which allows identification of subsets that respond better to treatment. A focused drug development approach will lead to a winwin for patients, payers, and sponsors. Pharma now focuses on subset specific trials rather than trials in broadly defined tumors; interactions between basic scientists, clinical researchers and diagnostic partners are essential to achieve meaningful progress against cancer.

The challenges are many: how to recognize the right data to identify patient subsets and the technology to select patients with sufficient rigor to drive drug development in addition to meeting regulatory requirements that may not keep pace with advancing technology. Pharma must learn how to select the best academic and diagnostic partners. Research is essential for progress against cancer, but funding is limited for collaboration between academia and industry. It takes considerable effort and time to bring partners really together, some of which is simply related to trust.

For the timely development of a diagnostic, a commercial partner may be preferred over an academic partner; however, the expertise of academic partners cannot be lost. Academic institutions compete with each other and thus choice of collaborators can be challenging.

In 2010 the Pharma priorities in oncology are driven by an unmet need and a targeted scientific hypothesis. By targeting the right pathway with optimal academic and diagnostic partners, medicines can be delivered to the right patient at the right time sooner.
Pharma today is and must be more cost-aware, must define efficacy for targeted agents consistently and, most of all, must let science drive the market rather than the reverse.

\section{Abbreviations}

ALK, anaplastic lymphoma kinase; NSCLC, non-small cell lung cancer.

\section{Competing interests}

MK is an employee and stock holder of Pfizer Pharmaceutical.

\section{Acknowledgements}

This article has been published as part of Breast Cancer Research Volume 12 Supplement 4, 2010: Controversies in Breast Cancer 2010. The full contents of the supplement are available online at http://breast-cancer-research.com/ supplements/12/S4

Published: 20 December 2010

\section{References}

1. Zou HY, Li Q, Lee JH, Arango ME, McDonnell SR, Yamazaki S, Koudriakova TB, Alton G, Cui JJ, Kung PP, Nambu MD, Los G, Bender SL, Mroczkowski B, Christensen JG: An orally available small-molecule inhibitor of c-Met, PF-2341066, exhibits cytoreductive antitumor efficacy through antiproliferative and antiangiogenic mechanisms. Cancer Res 2007, 67:4408-4417.

2. Soda M, Choi YL, Enomoto M, Takada S, Yamashita Y, Ishikawa S, Fujiwara S, Watanabe H, Kurashina K, Hatanaka H, Bando M, Ohno S, Ishikawa Y, Aburatani H, Niki T, Sohara Y, Sugiyama Y, Mano H: Identification of the transforming EML4-ALK fusion gene in non-small-cell lung cancer. Nature 2007, 448:561-566

3. Rodig SJ, Mino-Kenudson M, Dacic S, Yeap BY, Shaw A, Barletta JA, Stubbs H, Law K, Lindeman N, Mark E, Janne PA, Lynch T, Johnson BE, Lafrate J, Chirieac LR: Unique clinicopathologic features characterize ALK-rearranged lung adenocarcinoma in the western population. Clin Cancer Res 2009, 15:5216-5223

4. Bang Y, Kwak EL, Shaw AT, Camidge DR, lafrate AJ, Maki RG, Solomon BJ, Ou SI, Salgia R, Clark JW: Clinical activity of the oral ALK inhibitor PF-02341066 in ALK-positive patients with non-small cell lung cancer (NSCLC). J Clin Oncol 2010, 28:18S (suppl; abstr 3).

doi:10.1186/bcr2750

Cite this article as: Koehler M: Deciding priorities in Pharma. Breast Cancer Research 2010, 12(Suppl 4):S21 